\title{
Novel insights into the role of immune cells in skin and inducible skin-associated lymphoid tissue (iSALT)
}

Sachiko Ono, Kenju Kabashima

Department of Dermatology, Kyoto University Graduate School of Medicine, Kyoto, Japan

Key words

iSALT - SALT dermal dendritic

cell - macrophage - cluster-

ing $-\mathrm{T}$ cell

\section{Submitted}

March 24, 2015

\section{Accepted}

May 11, 2015

\section{Summary}

The skin is equipped with serial barriers that provide rapid and efficient protection against external intruders. Beneath the epidermal physical barriers of the stratum corneum and the tight junctions, the integrated immune systems in both the epidermis and the dermis act in a coordinated manner to protect the host. This "immunological" barrier is composed of various cells, including skin-resident cells, such as keratinocytes, dendritic cells, tissue-resident macrophages, resident memory T cells, mast cells, and innate lymphoid cells. Additionally, infiltrating memory T cells, monocytes, neutrophils, basophils, and eosinophils are recruited in support of the host immunity.

In addition to discussing the role of each of these cellular populations, we describe the concept of skin

\section{Introduction}

The skin is one of the largest organs in the human body and the primary interface with the external environment. Highly sophisticated protective systems have evolved in the skin to defend the body against external intruders. The protective components of mammalian skin include both physical and immunological barriers.

The stratum corneum (SC) and the tight junctions (TJs) work at the epidermal level as the most important "physical" barriers [1]. Beneath them, the integrated innate and acquired immune systems in both the epidermis and the dermis, which are activated in a coordinated manner to neutralize the intruders, are the most important "immunological" barriers. The immunological barrier consists of skinresident cells, such as keratinocytes (KCs), dendritic associated lymphoid tissue (SALT), which reminds us that the skin is an important component of the lymphatic system. We further describe the newly discovered phenomenon of multiple cell gathering under skin inflammation, which can be referred to as inducible SALT (iSALT). iSALT contributes to our understanding of SALT by highlighting the importance of direct cell-cell interaction in skin immunity.

Cite this as Ono S, Kabashima K. Novel insights into the role of immune cells in skin and inducible skin-associated lymphoid tissue (iSALT). Allergo J Int 2015;24:170-9

DOI: $10.1007 /$ s40629-015-0065-1 cells (DCs), tissue-resident macrophages, mast cells, resident memory $\mathrm{T}$ cells, and innate lymphoid cells (ILCs). In addition, infiltrating memory $\mathrm{T}$ cells, monocytes, neutrophils, basophils, and eosinophils are recruited to the skin under inflammation to support and coordinate host immunity.

In this review, we present the current knowledge on immune cells in the skin, which play important roles to establish or diminish the skin inflammation. We also revisit the established concept of skin-associated lymphoid tissue (SALT) [2], which reminds us that the skin is not only a peripheral site of inflammation but also an essential component of the lymphatic system.

Finally, we introduce the recently proposed concept of inducible SALT (iSALT), which has yielded novel insights into the roles of dermal DCs (dDCs) 
and macrophages in contact allergy by clarifying the details of cellular interactions in a murine contact hypersensitivity (CHS) model [3]. The concept of iSALT sheds light on the importance of the sequential cell-cell interactions among immune cells in situ for the establishment of skin inflammation.

\section{Epidermis \\ Keratinocytes}

The human epidermis consists of two major populations: KCs and Langerhans cells (LCs). It has gradually been discovered that KCs play important immunological roles in addition to their structural role [4]. KCs are able to sense various exogenous harmful pathogens and endogenous cellular damages through pattern recognition receptors (PRRs), which exist both on the cellular membranes and in the cytosol, to mediate immune responses. First, KCs express various Toll-like receptors (TLRs): TLR1, TLR2, TLR4, TLR5, and TLR6 on cell surfaces, and TLR3, TLR7, and TLR9 in endosomes [5,
$6,7,8,9]$. Pathogen-associated molecular patterns (PAMPs) of microbial origin, such as lipopolysaccharide (LPS), peptidoglycan, flagellin, and nucleic acids are sensed by some of these TLRs. Signals from these receptors facilitate the secretion of numerous cytokines, including interleukin (IL)-1 family (IL-1 $\alpha$, IL-1 $\beta$, and IL-33), IL-6, and tumor necrosis factor (TNF). Immune responses generated by different TLRs seem to be distinct, and numerous chemokines are secreted to attract various leukocytes depending on the type of inflammation. Activated KCs are also capable of conditioning LCs or DCs to promote predominant T helper (Th)1-, Th2-, or Th17-type immune responses through TLR signaling [10] or the secretion of different types of cytokines [11].

KCs also sense endogenous damage-associated molecular patterns (DAMPs), which are released from stressed host cells as a result of exogenous insults including infection, intoxications, and traumas. Adenosine triphosphate (ATP), heat shock pro-

\begin{tabular}{|c|c|c|c|}
\hline \multicolumn{4}{|c|}{ Abbrevations } \\
\hline$A D$ & Atopic dermatitis & IL & Interleukin \\
\hline Ags & Antigens & ILCs & Innate lymphoid cells \\
\hline AMPs & Anti-microbial peptides & iSALT & Inducible SALT \\
\hline APCs & Antigen presenting cells & $\mathrm{KCs}$ & Keratinocytes \\
\hline \multirow[t]{2}{*}{ ASC } & \multirow{2}{*}{$\begin{array}{l}\text { Apoptosis-associated speck like protein } \\
\text { containing a caspase recruitment domain }\end{array}$} & LCs & Langerhans cells \\
\hline & & LPS & Lipopolysaccharide \\
\hline ATP & Adenosine triphosphate & M1 & Classically activated macrophage \\
\hline CCL5 & Chemokine $\mathrm{C}-\mathrm{C}$ motif ligand 5 & M2 & Alternatively activated macrophage \\
\hline CHS & Contact hypersensitivity & MALT & Mucosa-associated lymphoid tissue \\
\hline CXCL2 & Chemokine C-X-C motif ligand 2 & Mgl2 & Macrophage galactose $\mathrm{C}$-type lectin type 2 \\
\hline CX3CR1 & C-X3-C chemokine receptor 1 & $\mathrm{MHC}$ & Major histocompatibility complex \\
\hline CXCR2 & Chemokine $\mathrm{C}-\mathrm{X}-\mathrm{C}$ motif receptor 2 & MLCs & Memory lymphocyte clusters \\
\hline $\begin{array}{l}\text { DAMPs } \\
\text { CDCs }\end{array}$ & $\begin{array}{l}\text { Damage-associated molecular patterns } \\
\text { Dermal conventional DCs }\end{array}$ & NLR & $\begin{array}{l}\text { Nucleotide-binding domain and leucine- } \\
\text { rich repeat containing family }\end{array}$ \\
\hline $\mathrm{dDCs}$ & Dermal DCs & PAMPs & Pathogen-associated molecular patterns \\
\hline DCs & Dendritic cells & $\mathrm{pDCs}$ & Plasmacytoid dendritic cells \\
\hline dLNs & Draining lymph nodes & PRRs & Pattern recognition receptors \\
\hline DN & Double negative & SALT & Skin associated lymphoid tissue \\
\hline \multirow{2}{*}{ dSEARCH } & \multirow{2}{*}{$\begin{array}{l}\text { Dendrite surveillance extension and } \\
\text { retraction cycling habitude }\end{array}$} & SC & Stratum corneum \\
\hline & & Th & Thelper \\
\hline DTA & Diphtheria toxin subunit A & TJs & Tight junctions \\
\hline DTR & Diphtheria toxin receptor & TLRs & Toll-like receptors \\
\hline HMGB1 & High-mobility group box protein 1 & TNF & Tumor necrosis factor \\
\hline HSV-2 & Herpes simplex virus & TSLP & Thymic stromal lymphopoietin \\
\hline IFN & Interferon & XCR1 & XC-chemokine receptor 1 \\
\hline
\end{tabular}


teins, hyaluronan, monosodium urate, galectins, adenosine, high-mobility group box protein 1 (HMGB1), IL-1a, and IL-33 have been identified as DAMPs [12]. DAMPs are sensed through a cytosolic inflammasome complex, which is formed by NLR (nucleotide-binding domain and leucine-rich repeat containing family), ASC (apoptosis-associated speck like protein containing a caspase recruitment domain), and pro-caspase-1 in the cytoplasm $[13,14]$. Activation of the inflammasome complex leads to subsequent activation of proinflammatory cytokines such as IL-1 $\beta$ and IL-18 [13]. Although it remains unclarified which DAMPs are sensed by KCs, KCs are reported to express NLR and thus considered to sense these DAMPs $[4,15]$. In addition to being a sensor, KCs can also be a source of DAMPs, such as ATP [16], HMGB1 [17], IL-1, and IL-33 during inflammation $[18,19]$.

Furthermore, KCs secrete anti-microbial peptides(AMPs), namely, $\beta$-defensins and cathelicidins. The secretion of these AMPs is increased in a Th17 cell-derived cytokine-dependent manner, with IL$17 \mathrm{~A}$ and IL-22 having a particularly strong effect [20]. These peptides act to protect against infectious microbes by direct killing of the pathogens, recruitment of host immune cells, and modulation of cytokine production. AMPs are essential for host defense as demonstrated by sterile inflammation and decreased skin infections in psoriatic skin lesions, wherein high expression of AMPs is noted, regardless of a dysfunctional epidermal barrier [2123]. Likewise, decreased AMPs and increased susceptibility to infection in atopic dermatitis (AD) patients has been indicated [24]. On top of its role in host defense, AMPs seem to be involved in the pathogenesis of psoriasis, because cathelicidin activates plasmacytoid DCs (pDCs), an important chaperon in psoriasis, after being coupled with selfDNA [25].

\section{Langerhans cells}

LCs are highly specialized antigen presenting cells (APCs) that account for approximately $2-4 \%$ of the total epidermal cell population [26]. They are characterized as the intraepithelial subpopulation of DCs, and their functions are distinct from those of dermal DCs.

Architecturally, LCs form dense cellular networks in the basal and suprabasal layers of the epidermis. Various surface markers characterize human and murine LCs (Tab. 1). Langerin/CD207 is the lectin receptor that binds mannose and related sugars found on a variety of microorganisms. CD205 is the essential molecule for antigen capturing and processing. Human LCs also highly express CD1a, which is capable of presenting microbial lipid antigen to $\mathrm{T}$ cells [27].
After sensing inflammatory signals, LCs undergo subsequent morphological and physiological changes: they increase in size and begin a motion of the dendritic processes known as dendrite surveillance extension and retraction cycling habitude (dSEARCH) [28]. Importantly, a recent report has demonstrated that LCs elongate their dendrites to penetrate the TJs to capture external antigens (Ags) that have violated the SC barrier [29]. After capturing Ags, LCs undergo maturation and then migrate from the epidermis to the draining lymph nodes (dLNs). Therein, LCs present the Ags to T cells, enabling epicutaneous sensitization of protein Ags.

The importance of LCs in the sensitization of protein Ags has been exhibited in an ovalbumin-induced murine AD model, in which LC deficiency reduced clinical symptoms and Ag-specific IgE production [30]. These findings support the idea that LCs are primarily responsible for capturing protein Ags, which cannot penetrate the physical epidermal barriers.

The role of LCs in the CHS reaction is a matter of debate. First, LC-deficient murine model of transgenic Langerin-DTA (diphtheria toxin subunit A) exhibited enhanced CHS and proposed a regulatory rather than a stimulatory role of LCs in the sensitization phase against haptens, although there remained the possibility that constitutive LC deficiency might result in abnormal compensatory effect of $\mathrm{T}$ cells in the model $[31,32]$. With an additional observation of the Langerin-specific IL-10 deletion model, the authors concluded that the suppressive effect of LCs requires their IL-10 production for inducing $\mathrm{CD}^{+}{ }^{+}$regulatory $\mathrm{T}$ (Treg) cells [34]. Because IL-10 from Langerin ${ }^{+} \mathrm{dDC}$ is also likely to have a similar suppressive effect in this model, further investigation is expected. The protective role of LCs in CHS by tolerizing CD8 T cells and activating Treg cells has also been demonstrated [34]. Besides, the observations of inducible LC-specific ablation strategy using Langerin-DTR(diphtheria toxin receptor)-knocked-in mice and of mice lacking LCs due to independent molecular defects show that LCs and dDCs seem to have a functional redundancy $[35,36,37,38,39]$. Accumulating literatures support the concept that rather the hapten dose determines the requirement for LCs for efficient $\mathrm{T}$ cell priming, and the number of skin DCs, but not the type of DCs, regulates the strength of the CHS reaction [31, $36,40]$.

Studies of other skin inflammation models, such as cutaneous leishmaniasis, indicate a tolerogenic function of LCs in vivo [41]. Likewise, in the absence of antigen presentation by dDCs, antigen presentation to CD4 T cells by LCs alone is unable to mediate $T$ cell differentiation in vivo $[42,43]$. In addition, a distinct function of LCs from dDCs has 
been indicated from the recent studies of the skin Candida albicans infection model. Ag presentation by LCs is essential for the generation of Ag-specific Th17 cells, whereas Langerin ${ }^{+}$dDCs are required for the generation of Ag-specific cytotoxic T cells and Th1 cells [44]. Intriguingly, the morphology of Candida albicans seems to be important for driving such distinct $\mathrm{T}$ cell responses [45].

\section{Dermis}

\section{Dermal dendritic cells}

Some foreign Ags, such as haptens, are small enough to penetrate the dermis across the TJs. When epidermal physical barriers are disrupted by cutaneous inflammation or scarring, larger molecules also become capable of entering the dermis directly. dDCs efficiently capture and present these Ags to initiate acquired immunity.

From the recent literatures [46, 47, 48], besides pDCs that are absent from the skin in the steady state, at least five DC populations are identified in the murine dermis: LCs in transit, monocyte-derived DCs that originate from $\mathrm{Ly}_{6} \mathrm{C}^{+}$blood monocytes, and dermal conventional DCs (cDCs) that originate from blood-borne precursors. $\mathrm{cDCs}$ consist of XC-chemokine receptor 1 (XCR1) ${ }^{+} \mathrm{cDCs}$,

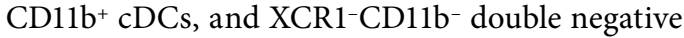
(DN) cDCs $[49,50,51]$. In detail, XCR1 ${ }^{+} \mathrm{cDCs}$ are composed of $\mathrm{CD} 03^{+} \mathrm{cDCs}$ and $\mathrm{CD} 103^{-} \mathrm{cDCs}$. $\mathrm{XCR}^{+}{ }^{+} \mathrm{cDCs}$ are the only subset to express high levels of Langerin/CD207 among dDCs, and are often called as Langerin ${ }^{+}$dDCs. LCs and CD11b- cDCs are also shown to express CD301b, also known as macrophage galactose C-type lectin type $2(\mathrm{Mgl} 2)$ $[45,52]$. Other several different surface markers are used to distinguish each population (Tab. 1). Similar DC subsets are also noticedin the human skin.

Compared to other dDC subsets, $\mathrm{CD} 103^{+} \mathrm{cDCs}$ are highly efficient at cross-presenting Ags to naive
$\mathrm{CD}^{+} \mathrm{T}$ cells, and likely promote Th1 immune responses $[44,53,54]$. As mentioned above, Langerin ${ }^{+}$ $\mathrm{dDCs}$ are shown to induce Th1 cells during cutaneous Candida albicans infection [44]. On the other hand, in the sensitization phase of CHS, various literatures indicate the importance and redundancy of different DC types, including LCs, Langerin ${ }^{+}$ dDCs, and CD11b ${ }^{+}$cDCs $[45,52,55,56]$. The hapten dose and the number of DCs seem to be important, as discussed in the chapter of LCs.

The importance of CD11 $\mathrm{b}^{+} \mathrm{dDC}$ in the generation of Th2 immune responses has also been suggested $[52,57]$. The function and characteristics of DN cDCs remain uninvestigated.

Which T cell responses (Th1-, Th2-, and/or Th17type) are promoted in dLNs is considered to depend not only on dDC types, but also on the local skin conditions, under which dDCs are activated. For example, in AD, thymic stromal lymphopoietin (TSLP) is massively expressed from the epidermis in the presence of mechanical injury [58]. TSLP receptor signaling through LCs and dDCs activates and upregulates OX40L on those cells, leading to subsequent skewing into Th2-type responses [59]. Likewise, IL-33 is one of the IL-1 family members derived from KCs, and it also mediates Th2-type responses [19].

Psoriasis was classically defined as Th1- and Th17type inflammation. KC-derived IL-1 $\beta$, IL-6, and TNF- $\alpha$ and pDC-derived IFN- $\alpha$ are thought to activate local dDCs, leading to IL-23 secretion to prime naive $\mathrm{T}$ cells into Th1 and/or Th17 sets in dLNs [4, 60]. Recently, the significance of IL-23/ IL-17/IL-22 axis in psoriasis has become more evident from genome wide studies, the efficacy of biologics targeting these cytokines, and reduction in these cytokines after disease amelioration $[61,62$, 63]. It has attracted the attention again which DC subsets play a pivotal role in producing IL-23 and in

Tab. 1: Surface markers of Langerhans cells (LCs) and dermal dendritic cells (dDCs)

\begin{tabular}{|c|c|c|c|c|c|c|}
\hline & Occupation & \multicolumn{3}{|c|}{ Murine surface markers } & \multicolumn{2}{|c|}{ Human surface markers } \\
\hline LCs & $\begin{array}{l}2-4 \% \text { of } \\
\text { epidermal cells }\end{array}$ & \multirow{5}{*}{$\begin{array}{l}{\mathrm{CD} 45^{+}, \mathrm{MHC}}{\text { class } \mathrm{II}^{+},} \\
\mathrm{CD} 11 \mathrm{C}^{+} \text {, } \\
\text { T/B/NK cell } \\
\text { markers', }\end{array}$} & \multicolumn{2}{|c|}{ 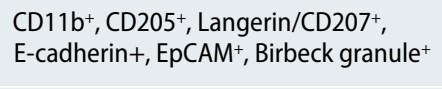 } & \multirow{5}{*}{$\begin{array}{l}\mathrm{CD}^{2} 45^{+}, \mathrm{MHC} \\
\text { class II+, }^{+} \\
\mathrm{CD} 11 \mathrm{c}^{+} \text {, } \\
\text { T/B/NK cell } \\
\text { markers }\end{array}$} & $\begin{array}{l}\text { E-cadherin }{ }^{+}, \mathrm{EpCAM}^{+}, \text {Langerin/CD207+, } \\
\text { Birbeck granule }{ }^{+}, \mathrm{CD} 1 \mathrm{a}^{+}\end{array}$ \\
\hline $\begin{array}{l}\text { Monocyte } \\
\text { derived dDCs }\end{array}$ & no data & & \multicolumn{2}{|l|}{$\mathrm{CD} 4^{\mathrm{low} /+}, \mathrm{CCR}^{+}$} & & $\mathrm{CD}_{14}^{+}$ \\
\hline $\mathrm{CD} 11 \mathrm{~b}^{+} \mathrm{cDCs}$ & $\begin{array}{l}50-70 \% \text { of } \\
\mathrm{dDC} \text { pool }\end{array}$ & & \multicolumn{2}{|c|}{$\begin{array}{l}\mathrm{CD} 11 \mathrm{~b}^{+}, \mathrm{CD} 301 \mathrm{~b}^{+}, \mathrm{CCR} 2^{+}, \mathrm{CD} 172 \mathrm{a}^{+} \text {, } \\
\mathrm{CX}_{3} \mathrm{CR} 1^{\text {mid }}\end{array}$} & & $\mathrm{CD}_{1} \mathrm{c}^{+}$ \\
\hline $\mathrm{XCR} 1+\mathrm{CDCs}$ & $\begin{array}{l}10-20 \% \text { of } \\
\text { dDC pool }\end{array}$ & & 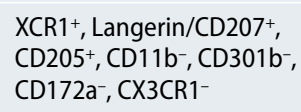 & $\begin{array}{l}\mathrm{CD}^{2} 3^{+} \\
\mathrm{CD} 103^{-}\end{array}$ & & $\mathrm{XCR} 1^{+}, \mathrm{CD} 141^{+}$ \\
\hline DN cDCs & no data & & \multicolumn{2}{|c|}{$\mathrm{CD} 11 \mathrm{~b}^{\text {low }}, \mathrm{CX}_{3} \mathrm{CR} 1^{\text {hi }}, \mathrm{CCR} 2^{+}, \mathrm{CD} 172 \mathrm{a}^{+}$} & & no data \\
\hline
\end{tabular}


differentiation and maintenance of IL-17- and IL-22-producing T cells. Recent reports have differently demonstrated the importance of LCs or Langerin $^{-} \mathrm{dDCs}$ in the development of a murine psoriasis-like skin lesion induced by a TLR7 agonist Imiquimod $[64,65]$. Another literature has shown that depletion of pDC resulted in the attenuated disease development, whereas depletion of LCs exacerbated the chronic phase of a different murine psoriasis model induced by keratinocyte-specific deletion of both Jun and JunB [66]. The discrepancy between these reports might be due to different models and protocols; however, this topic needs further investigation. Additionally, IL-36, a novel member of IL-1 family cytokines, has been identified as the master regulator of the IL-23/IL-17/IL-22 axis by enabling cross talk between KCs and DCs [67].

\section{Macrophages}

Macrophages are unique cells that have a strong phagocytic function for the clearance of unnecessary wastes, such as apoptotic cells, cellular debris, and pathogens. In addition to the clearance of waste disposal, they facilitate the induction of inflammation by Ag recognition via a wide array of receptors, and thus participate in innate and acquired immunity [68, $69,70]$. Moreover, they produce growth factors that stimulate capillary growth, collagen synthesis, and fibrosis, all of which are related to tissue repair. Thus, they play a fundamental role as the frontline of tissue defense and the organizer of tissue homeostasis.

Macrophages are functionally grouped into two classes: M1 (classically activated) and M2 (alternatively activated) [71,72], according to their role and the cytokines needed for their activation. M1 and M2 statuses are defined by a cell's response to interferon (IFN) $-\gamma$ and TLR signaling and to IL- 4 and IL-13, respectively. M1-type macrophages produce proinflammatory cytokines including IL-1 and destroy intracellular pathogens by means of an increased oxidative burst and nitric oxide production. Although the role of M2-type macrophages has been less well characterized, several functions have been noted, including involvement in protection against parasitic infections, promoting Th2 immune responses, damping excessive inflammation, tumor progression, angiogenesis, wound healing, tissue remodeling, and fibrosis $[73,74,75]$.

In mice, lymphocyte antigen 6C (Ly6C)-positive inflammatory monocytes, which express high amounts of chemokine receptor type 2 (CCR2) but low amounts of $\mathrm{C}-\mathrm{X} 3-\mathrm{C}$ chemokine receptor 1 (CX3CR1), enters from the circulation to the tissue and takes on the macrophage phenotype during inflammation. They are believed to act as M1-type macrophagess [75]. On the other hand, Ly6C-negative macrophages, which express high amounts of CX-
3CR1 but low amounts of CCR2, are considered as M2-type macrophages. Likewise, CD14-CD16 ${ }^{+}$ monocytes are classified as M1-type and $\mathrm{CD} 14^{+} \mathrm{CD} 16^{+}$macrophages as M2-type in humans $[76,77]$.Tissue-resident macrophages are classified as M2-type in general [72]. Phenotype transition from M1-type into M2-type has been reported under the stimulation by basophil-derived IL- 4 in the late phase of chronic allergic inflammation of the skin [77]. Although the different roles of macrophages derived from inflammatory monocytes and tissue-resident macrophages have not yet been accurately determined, each subset is believed to act in a coordinated manner in both inflammation and tissue-repair phases.

Tissue resident macrophages are densely distributed in the dermis, and their diverse anatomical distribution has been noted. They may be associated with blood vessels (perivascular macrophages) or lymphatic vessels, or may reside in the intervascular spaces [78]. Of note, a recent report has newly defined the important function of perivascular macrophages in neutrophil recruitment to the skin: neutrophil extravasation occurred in inflamed dermal vessels adjacent to perivascular macrophages, and neutrophil infiltration was inhibited when these macrophages were eliminated [79]. Another fundamental role of perivascular macrophages determined through iSALT will be discussed later.

\section{T cells}

$\mathrm{T}$ cells in their naive state first encounter APCs in secondary lymphoid organs. They are primed through Ag presentation by DCs and then proliferate and differentiate to adopt a memory phenotype. Non-lymphoid tissues, including the skin, serve as sites for such memory $\mathrm{T}$ cell infiltration because they tightly regulate the expression of adhesion molecules and chemokine receptors for memory $\mathrm{T}$ cell homing [80]. Memory T cells migrate into the peripheral tissue robustly under active inflammation; however, memory $\mathrm{T}$ cells also enter the tissue to scan for Ags even in the absence of inflammatory stimuli [81, 82].

The skin infiltrating CD4 T cells consist of Th1, Th2, Th17, Th22, Th9, and Treg cell subsets. It is generally believed that Th differentiation fate of each CD4 T cell is determined by the nature of the APCs that prime naive $\mathrm{T}$ cells in the dLNs, as discussed in the chapters on LCs and dDCs.

The essential role of Th1 cells is to protect against intracellular pathogens and viruses by secreting IFN- $\gamma$. They dominate in the skin during the early phase of contact dermatitis [83]. Th2 cells play a central role in allergic disorders such as AD by regulating both acute- and late-phase allergic reactions, mediated by immunoglobulin $\mathrm{E}$ and eosinophils, re- 
spectively. They function by secreting IL-4, IL-5, IL13, IL-24, IL-25, and IL-31. Full activation of Th2 cells is achieved through the cytokine production by $\mathrm{KCs}$, such as IL-33 and TSLP, and by subsequent activation of group 2 ILCs to produce IL-5, IL-9, and IL-13 [84]. Skin Th17 cells protect against bacteria and fungi, such as Staphylococcus aureus, Klebsiella pneumoniae, and Candida albicans, by controlling neutrophils at the mucocutaneous surfaces $[45,85]$. Th17 and Th22 cells are well known for their role in psoriasis. In psoriasis, KC-derived IL- $1 \beta$, IL- 6 , and TNF- $\alpha$ and plasmacytoid DC-derived IFN- $\alpha$ lead to Th17 cell-mediated inflammation. In turn, Th17 cells secrete IL-17A, IL-17F, and IL-22, which stimulate proliferation and abnormal differentiation of KCs.

CD8 $\mathrm{T}$ cells are the principal effector cells that recognize Ags on major histocompatibility complex (MHC) class I molecules. They are considered to be involved in various skin disorders [82] including contact dermatitis, psoriasis, graft versus host disease, vitiligo, alopecia areata [86], and drug eruptions [87]. After being primed by DCs, CD8 T cells circulate around the tissue having assumed a cytotoxic memory phenotype. They possess a strong capacity for eradicating Ag-bearing cells, such as virally infected cells, tumor cells, and grafted allogenic cells, upon re-exposure. Recent discoveries concerning the important functions of dDCs and macrophages in memory $\mathrm{CD} 8 \mathrm{~T}$ cell activation in the skin will be discussed later in the chapter on iSALT.

In a steady state, skin CD4 and CD8 T cells are essentially resident memory $\mathrm{T}$ cells, which mainly reside in the dermal perivascular area and the epidermis, respectively [88, 89]. Resident memory $\mathrm{T}$ cells comprise a functionally distinct, non-migratory population and persist long-term in peripheral tissues to provide effective protection against local Ag re-challenge. Although the mechanisms how the memory $T$ cell subset resides, and is maintained and re-activated in the peripheral tissue are not yet fully determined, they are considered to be derived from precursors that enter the tissue during the effector phase of immune responses [90]. The essential role of skin-resident memory T cells in local immunity remains an important issue to be clarified.

\section{SALT and iSALT: role of dendritic cells and macrophages}

In humans and rodents, lymphoid structures that consist of $\mathrm{T}$ and $\mathrm{B}$ cell areas can be observed in specialized submucosal areas. These structures are known as "mucosa-associated lymphoid tissue (MALT)" [91]. In MALT, the prompt and efficient antigen presentation to T cells and B cell class switching occur independently of secondary lymphoid organs.

In the 1980s, cutaneous immunologists introduced the term "skin-associated lymphoid tissue
(SALT)" based on multiple studies that revealed the existence of T cells and DCs in the skin under inflammatory conditions $[2,92,93]$. In the classical concept of SALT, it is supposed that antigen presentation to naive $\mathrm{T}$ cells occurs in the skin as it does in secondary lymphoid tissues or in MALT. However, in SALT, it remains unclear whether and how $\mathrm{T}$ cells are activated in the skin in situ. In addition, no distinct lymphoid structures have been observed in the skin in a steady state or even under inflammatory conditions, such as contact dermatitis and AD, in contrast to MALT. Therefore, SALT has remained conceptual for more than 30 years.

Recently, dDC clustering (Fig. 1a) around the post-capillary venules has been discovered in the elicitation phase of the CHS reaction [3] in a murine model for contact dermatitis. In this clustering, $\mathrm{dDCs}$ contact the effector T cells, leading to their activation. Both KCs and perivascular macrophages seem to play essential roles in this phenomenon, given that $\mathrm{dDC}$ clustering and effector $\mathrm{T}$ cell activation were abrogated in the absence of IL-1 signaling from $\mathrm{KCs}$ and macrophage-depleted mice. In addition, Chemokine (C-X-C motif) ligand 2 (CXCL2) was the major chemokine expressed by macrophages under stimulation with IL-1. Blocking of chemokine (C-X-C motif) receptor 2 (CXCR2), a CXCL2 receptor, also inhibited $\mathrm{dDC}$ clustering. Therefore, an inducible structure formed of perivascular macrophages, dDCs, and effector T cells is identified. Because the formation of this structure is essential for efficient activation of effector T cells, these inducible leukocyte clusters may function as SALTs. This structure was named "inducible SALT (iSALT)" (Fig. 1b) in analogy with inducible bronchus-associated lymphoid tissue (iBALT), which is involved in the respiratory immunity [94]. This clustering of dDCs and T cells was also observed in the skin of a contact dermatitis patient, demonstrating that iSALT forms in humans as well.

There are some major issues to be clarified with regard to iSALT. It should be determined whether iSALT enables naive $\mathrm{T}$ cell priming or B cell class switching and antibody production in situ, as in other lymphoid-associated tissues.

It should also be investigated whether iSALT or iSALT-like structures are established by other cells, or in other inflammatory settings, such as infection, psoriasis and $\mathrm{AD}$. The essential roles of various skin-associated cells, including KCs, DCs, macrophages, T cells, ILCs, mast cells, basophils, and eosinophils, in either establishment or cessation of cutaneous immune reactions have been revealed. Therefore, it is possible that other T cell subsets or ILCs utilize such structures for their activation in situ.

Further supporting this idea, the essential role of local macrophages for resident memory CD4 T cell maintenance and activation against herpes simplex 

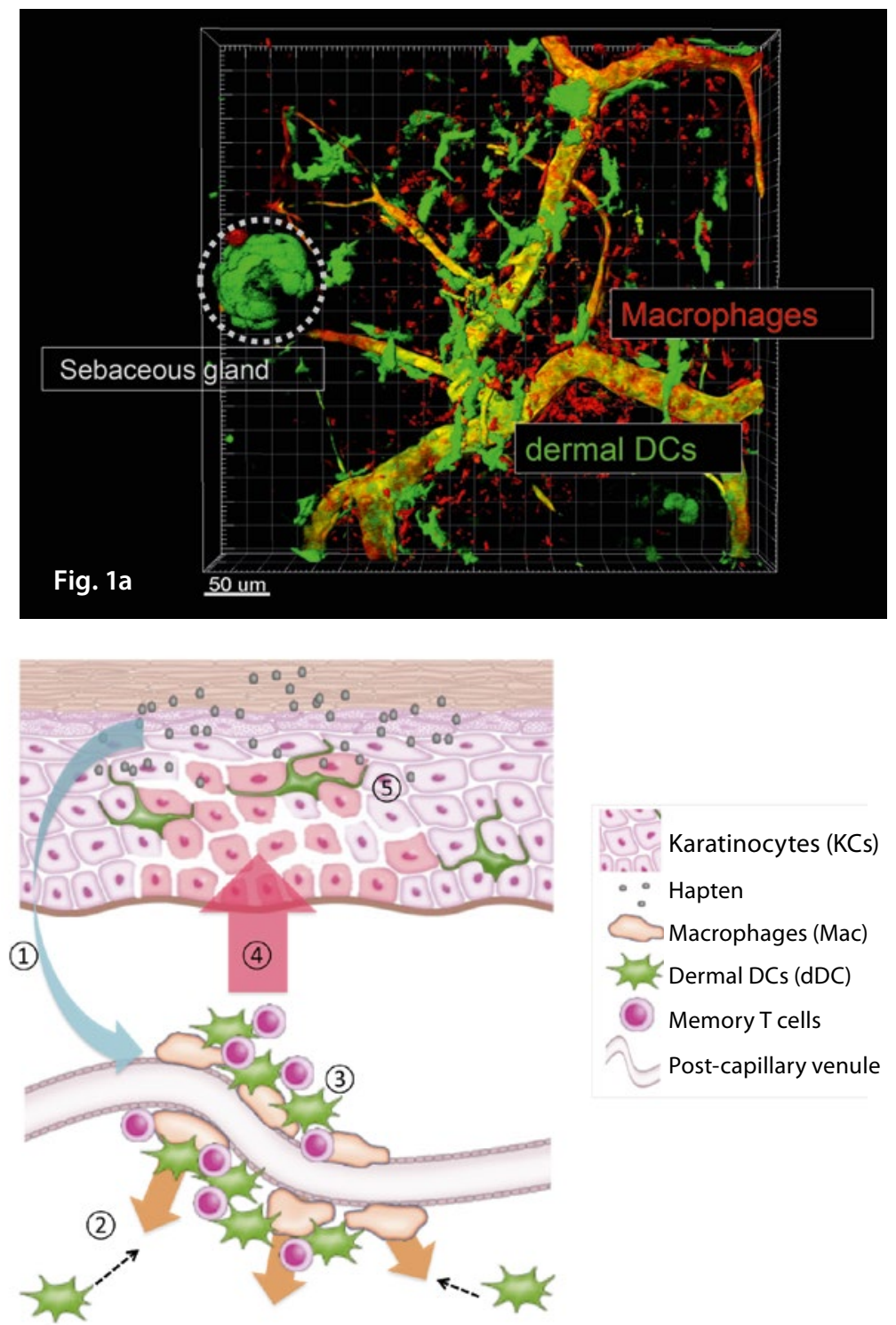

Fig. 1b

Fig. 1: Snapshot of dermal dendritic cell clustering and schema of iSALT. a: Cluster formation by dermal dendritic cells and perivascular macrophages was visualized in the ear skin dermis of CD11c YFP mice in the elicitation phase of $\mathrm{CHS}$, with some modification of the ref. 3. Scale bar $=100 \mathrm{um}$. . b: A schema of inducible skin associated lymphoid tissue (iSALT) in the elicitation phase of CHS. (1) = IL-1a secreted from KCs under stimulation by haptens activates perivascular macrophages. (2) = Perivascular macrophages secrete chemokine (C-X-C motif) ligand 2 (CXCL2), leading to dDC accumulation that express chemokine ( $\mathrm{C}-\mathrm{X}-\mathrm{C}$ motif) receptor $2(\mathrm{CXCR} 2)$. $3=\mathrm{dDC}$ clustering traps memory $\mathrm{T}$ cells at the site of extravasation. This perivascular macrophage-dDC-T cell clustering is considered to be iSALT. (4) = Memory T cells are activated to produce IFN- $\gamma$ through interaction with dDCs. (5) = Epidermal spongiosis (intercellular edema) occurs just above iSALT.

virus (HSV-2) in the genital mucosa has been reported [95]. Within the memory lymphocyte clusters (MLCs), secretion of basal levels of IFN- $\gamma$ from resident memory CD4 $\mathrm{T}$ cells activates macrophages, and secretion of chemokine (C-C motif) li- gand 5 (CCL5) from macrophages sustains resident memory CD4 T cells in turn. Upon Ag re-challenge, these $\mathrm{T}$ cells are activated to secrete high levels of IFN- $\gamma$. Even though the site of activation (the skin vs. the genital mucosa) and the activated cell types (CD8 vs. CD4 T cells; recruited vs. resident) are different between iSALT and MLCs, the two cluster-based structures are similar in several ways, and both emphasize the importance of local cell-cell interaction in acquired immune response.

Besides, DC-specific IL-10 receptor deficient mice failed to prevent exaggerated activation of memory $\mathrm{T}$ cells in the elicitation phase of CHS, which implicates the critical role of IL-10 control of DCs during T cell re-activation (= challenge) in the skin during CHS. This may also be an example of the importance of cellular crosstalk between Treg cells and DCs [96] in situ for the cessation of cutaneous immune reactions. It would be interesting to pursue whether Tregs are engaged in iSALT.

In addition, mature DC and T cell clustering has been proposed in psoriasis [97, 98], although its role in the pathogenesis of psoriasis remains uninvestigated. It is possible that such DC-T cell interaction in the skin is essential for memory Th1 or Th17 cell activation in psoriasis.

Moreover, it is of note that both basophils and ILC2 cells are reported to accumulate in the skin lesions of $\mathrm{AD}$ patients and a murine AD model, and that these two cells types tend toward locational proximity to each other [99]. This report shows that IL-4 produced by basophils is crucial for ILC2 cell proliferation at the site, suggesting the cross-regulation of ILC2 cells by basophils. Because basophils can act as APCs, the inducible basophil-ILC2 clusters in the skin suggest the possibility of another iSALT-like structure in the murine AD model.

Furthermore, distinct lymphoid structures other than iSALT have been reported under particular circumstances, such as cutaneous lupus erythematosus [100, 101], keloids (the aberrant overgrowth of scar tissue that occur at the skin injury site) [102], and pseudolymphoma [103, 104], although the underlying mechanisms remain to be clarified. The functional and pathological differences between iSALT and other skin lymphoid structures should be determined in the future.

\section{Conclusion}

Our understanding of the immunological role of each cellular subset in the skin and of their interactions has progressed steadily. Because each pathological condition involves various immune cell reactions and interactions, we should be careful to discriminate the immune reactions that occur in the peripheral organs from those that occur in the secondary lymphoid organs. This will help us to un- 
derstand the common and characteristic roles of each organ, including the skin. Much remains to [105] be clarified in the skin-resident immune network, especially with regard to iSALT.

\section{Kenji Kabashima MD, PhD}

Chair of the Department of Dermatology

Kyoto University Graduate School of Medicine

54 Shogoin-Kawara

Kyoto 606-8507, Japan

E-Mail:kaba@kuhp.kyoto-u.ac.jp

\section{Conflicts of interest}

The authors declare that there are no conflicts of interest.

\section{Cite this as}

Ono S, Kabashima K. Novel insights into the role of immune cells in skin and inducible skin-associated lymphoid tissue (iSALT). Allergo J Int 2015; 24: 170-9

\section{DOI: 10.1007/s40629-015-0065-1}

\section{References}

1. Kabashima K. New concept of the pathogenesis of atopic dermatitis: interplay among the barrier, allergy, and pruritus as a trinity. J Dermatol Sci 2013;70:3-11

2. Streilein JW. Skin-associated lymphoid tissues (SALT): origins and functions. J Invest Dermatol 1983; 80 Suppl: 12s-16s

3. Natsuaki Y, Egawa G, Nakamizo S, Ono S, Hanakawa S, Okada T, et al. Perivascular leukocyte clusters are essential for efficient activation of effector T cells in the skin. Nat Immunol 2014:15:1064-9

4. Nestle FO, Di Meglio P, Qin JZ, Nickoloff BJ. Skin immune sentinels in health and disease. Nat Rev Immunol 2009;9:679-91

5. Lebre MC, van der Aar AM, van Baarsen L, van Capel TM, Schuitemaker JH, Kapsenberg ML, et al. Human keratinocytes express functional Toll-like receptor 3, 4, 5, and 9. J Invest Dermatol 2007;127:331-41

6. Begon E, Michel L, Flageul B, Beaudoin I, Jean-Louis F, Bachelez $\mathrm{H}$, et al. Expression, subcellular localization and cytokinic modulation of Toll-like receptors (TLRs) in normal human keratinocytes: TLR2 up-regulation in psoriatic skin. Eur J Dermatol 2007;17:497-506

7. Selleri S, Arnaboldi F, Palazzo M, Gariboldi S, Zanobbio L, Opizzi E, et al. Toll-like receptor agonists regulate beta-defensin 2 release in hair follicle. Br J Dermatol 2007;156:1172-7

8. Muller-Anstett MA, Muller P, Albrecht T, Nega M, Wagener J, Gao Q, et al. Staphylococcal peptidoglycan co-localizes with Nod2 and TLR2 and activates innate immune response via both receptors in primary murine keratinocytes. PLoS One 2010;5:e13153

9. Sugita K, Kabashima K, Atarashi K, Shimauchi T, Kobayashi $M$, Tokura $Y$. Innate immunity mediated by epidermal keratinocytes promotes acquired immunity involving Langerhans cells and T cells in the skin. Clin Explmmunol 2007;147:176-83

10. Miller LS, Modlin RL. Human keratinocyte Toll-like receptors promote distinct immune responses. J Invest Dermatol 2007;127:262-3

11. Soumelis V, Reche PA, Kanzler H, Yuan W, Edward G, Homey $B$, et al. Human epithelial cells trigger dendritic cell mediated allergic inflammation by producing TSLP. Nat Immunol 2002;3:673-80

12. Hirsiger S, Simmen HP, Werner CM, Wanner GA, Rittirsch D. Danger signals activating the immune response after trauma. Mediators Inflamm 2012; 2012: 315941

13. Martinon F, Mayor A, Tschopp J. The inflammasomes: guardians of the body. Annu Rev Immunol 2009;27:22965

14. Fukata M, Vamadevan AS, Abreu MT. Toll-like receptors (TLRs) and Nod-like receptors (NLRs) in inflammatory disorders. Semin Immunol 2009:21:242-53

15. Feldmeyer L, Keller M, Niklaus G, Hohl D, Werner S, Beer $\mathrm{HD}$. The inflammasome mediates UVB-induced activation and secretion of interleukin-1beta by keratinocytes. Curr Biol 2007:17:1140-5

16. Burrell HE, Wlodarski B, Foster BJ, Buckley KA, Sharpe GR, Quayle JM, et al. Human keratinocytes release ATP and utilize three mechanisms for nucleotide interconversion at the cell surface. J Biol Chem 2005;280:29667-76

17. Nakajima S, Watanabe $H$, Tohyama $M$, Sugita K, lijima M, Hashimoto K, et al. High-mobility group box 1 protein (HMGB1) as a novel diagnostic tool for toxic epidermal necrolysis and Stevens-Johnson syndrome. Arch Dermatol2011;147:1110-2

18. Mattii M, Ayala F, Balato N, Filotico R, Lembo S, Schiattarella $\mathrm{M}$, et al. The balance between pro- and anti-inflammatory cytokines is crucial in human allergic contact dermatitis pathogenesis: the role of IL-1 family members. Exp Dermatol 2013;22:813-9

19. Schmitz J, Owyang A, Oldham E, Song Y, Murphy E, MCClanahan TK, et al. IL-33, an interleukin-1-like cytokine that signals via the IL-1 receptor-related protein ST 2 and induces T helper type 2-associated cytokines. Immunity 2005;23:479-90

20. Liang SC, Tan XY, Luxenberg DP, Karim R, Dunussi-Joannopoulos K, Collins M, et al. Interleukin (IL)-22 and IL-17 are coexpressed by Th17 cells and cooperatively enhance expression of antimicrobial peptides. J Exp Med 2006;203:2271-9

21. Harder J, Bartels J, Christophers E, Schroder JM. A peptide antibiotic from human skin. Nature 1997;387:861

22. Henseler T, Christophers E. Disease concomitance in psoriasis. J Am Acad Dermatol1995;32:982-6

23. de Jongh GJ, Zeeuwen PL, Kucharekova M, Pfundt R, van der Valk PG, Blokx W, et al. High expression levels of keratinocyte antimicrobial proteins in psoriasis compared with atopic dermatitis. J Invest Dermatol 2005;125:1163-73

24. Ong PY, Ohtake T, Brandt C, Strickland I, Boguniewicz M, Ganz T, et al. Endogenous antimicrobial peptides and skin infections in atopic dermatitis. N Engl J Med 2002:347:1151-60

25. Lande R, Gregorio J, Facchinetti V, Chatterjee B, Wang YH, Homey $B$, et al. Plasmacytoid dendritic cells sense selfDNA coupled with antimicrobial peptide. Nature 2007:449:564-9

26. Valladeau J, Saeland S. Cutaneous dendritic cells. Semin Immunol 2005; 17: 273-83

27. Hunger RE, Sieling PA, Ochoa MT, Sugaya M, Burdick AE, Rea $\mathrm{TH}$, et al. Langerhans cells utilize CD1a and langerin to efficiently present nonpeptide antigens to T cells. J Clin Invest 2004;113:701-8

28. Nishibu A, Ward BR, Jester JV, Ploegh HL, Boes M, Takashima A. Behavioral responses of epidermal Langerhans cells in situ to local pathological stimuli. J Invest Dermatol 2006;126:787-96

29. Kubo A, Nagao K, Yokouchi M, Sasaki H, Amagai M. External antigen uptake by Langerhans cells with reorganization of epidermal tight junction barriers. J Exp Med 2009:206:2937-46

30. Nakajima S, Igyarto BZ, Honda T, Egawa G, Otsuka A, Hara-Chikuma $\mathrm{M}$, et al. Langerhans cells are critical in epicutaneous sensitization with protein antigen via thymic stromal lymphopoietin receptor signaling. J Allergy Clin Immunol 2012;129:1048-55 e6

31. Kaplan DH, Kissenpfennig A, Clausen BE. Insights into Langerhans cell function from Langerhans cell ablation models. Eur J Immunol 2008;38:2369-76

32. Igyarto BZ, Jenison MC, Dudda JC, Roers A, Muller W, Koni 
PA, et al. Langerhans cells suppress contact hypersensitivity responses via cognate CD4 interaction and langerhans cell-derived IL-10. J Immunol 2009;183:5085-93

33. Yoshiki R, Kabashima K, Sugita K, Atarashi K, Shimauchi T, Tokura Y. IL-10-producing Langerhans cells and regulatory $T$ cells are responsible for depressed contact hypersensitivity in grafted skin. J Invest Dermatol 2009;129:705-13

34. Gomez de Aguero M, Vocanson M, Hacini-Rachinel F, Taillardet M, Sparwasser T, Kissenpfennig A, et al. Langerhans cells protect from allergic contact dermatitis in mice by tolerizing CD8(+) T cells and activating Foxp3(+) regulatory T cells. J Clin Invest 2012;122:1700-11

35. Bennett $C L$, van Rijn E, Jung $S$, Inaba K, Steinman RM, Kapsenberg ML, et al. Inducible ablation of mouse Langerhans cells diminishes but fails to abrogate contact hypersensitivity. J Cell Biol 2005;169:569-76

36. Noordegraaf M, Flacher V, Stoitzner P, Clausen BE. Functional redundancy of Langerhans cells and Langerin+ dermal dendritic cells in contact hypersensitivity. J Invest Dermatol 2010;130:2752-9

37. Kuipers H, Schnorfeil FM, Fehling HJ, Bartels $\mathrm{H}$, Brocker $\mathrm{T}$. Dicer-dependent microRNAs control maturation, function, and maintenance of Langerhans cells in vivo. J Immunol 2010;185:400-9

38. ahner SP, Kel JM, Martina CA, Brouwers-Haspels I, van Roon MA, Clausen BE. Conditional deletion of TGFbetaR1 using Langerin-Cre mice results in Langerhans cell deficiency and reduced contact hypersensitivity. J Immunol 2011:187:5069-76

39. Kel JM, Girard-Madoux MJ, Reizis B, Clausen BE. TGF-beta is required to maintain the pool of immature Langerhans cells in the epidermis. J Immunol 2010;185:3248-55

40. Romani N, Clausen BE, Stoitzner P. Langerhans cells and more: langerin-expressing dendritic cell subsets in the skin. Immunol Rev2010;234:120-41

41. Kautz-Neu K, Noordegraaf $M$, Dinges $S$, Bennett $C L$, John $D, C l a u s e n$ BE, et al. Langerhans cells are negative regulators of the anti-Leishmania response. J Exp Med 2011;208:885-91

42. Shklovskaya E, O'Sullivan BJ, Ng LG, Roediger B, Thomas $\mathrm{R}$, Weninger $\mathrm{W}$, et al. Langerhans cells are precommitted to immune tolerance induction. Proc Natl Acad Sci U S A 2011;108:18049-54

43. Ritter U, Meissner A, Scheidig C, Korner H. CD8 alphaand Langerin-negative dendritic cells, but not Langerhans cells, act as principal antigen-presenting cells in leishmaniasis. Eur J Immunol 2004;34:1542-50

44. Igyarto BZ, Haley K, Ortner D, Bobr A, Gerami-Nejad M, Edelson BT, et al. Skin-resident murine dendritic cell subsets promote distinct and opposing antigen-specific $T$ helper cell responses. Immunity 2011;35:260-72

45. Kashem SW, Igyarto BZ, Gerami-Nejad M, Kumamoto $Y$, Mohammed J, Jarrett E, et al. Candida albicans Morphology and Dendritic Cell Subsets Determine T Helper Cell Differentiation. Immunity 2015;42:356-66

46. Malissen B, Tamoutounour S, Henri S. The origins and functions of dendritic cells and macrophages in the skin. Nat Rev Immunol 2014;14:417-28

47. Henri S, Poulin LF, Tamoutounour S, Ardouin L, Guilliams $M$, de Bovis B, et al. CD207+ CD103+ dermal dendritic cells cross-present keratinocyte-derived antigens irrespective of the presence of Langerhans cells. J Exp Med 2010;207:189-206

48. Tamoutounour S, Guilliams M, Montanana Sanchis F, Liu $H$, Terhorst $D$, Malosse $C$, et al. Origins and functional specialization of macrophages and of conventional and monocyte-derived dendritic cells in mouse skin. Immunity 2013;39:925-38

49. Poulin LF, Henri S, de Bovis B, Devilard E, Kissenpfennig A, Malissen $B$. The dermis contains langerin+ dendritic cells that develop and function independently of epidermal Langerhans cells. J Exp Med 2007;204:3119-31
50. Ginhoux F, Liu K, Helft J, Bogunovic M, Greter M, Hashimoto D, et al. The origin and development of nonlymphoid tissue CD103+ DCs. J Exp Med 2009;206:311530

51. Shklovskaya E, Roediger B, Fazekas de St Groth B. Epidermal and dermal dendritic cells display differential activation and migratory behavior while sharing the ability to stimulate CD4(+) T cell proliferation in vivo. J Immunol 2008;181:418-430

52. Kumamoto $Y$, Linehan $M$, Weinstein JS, Laidlaw BJ, Craft JE, Iwasaki A. CD301b(+) dermal dendritic cells drive T helper 2 cell-mediated immunity. Immunity 2013;39:73343

53. Bedoui S, Whitney PG, Waithman J, Eidsmo L, Wakim L, Caminschi l, et al. Cross-presentation of viral and self antigens by skin-derived CD103(+) dendritic cells. Nat Immunol 2009;10:488-95

54. 54. Henri S, Poulin LF, Tamoutounour S, Ardouin L, Guilliams M, de Bovis B, et al. CD207(+) CD103(+) dermal dendritic cells cross-present keratinocyte-derived antigens irrespective of the presence of Langerhans cells (vol 207, pg 189, 2010). J Exp Med 2010;207:445-445

55. Bursch LS, Wang L, Igyarto B, Kissenpfennig A, Malissen B, Kaplan DH, et al. Identification of a novel population of Langerin(+) dendritic cells. J Exp Med 2007;204:31473156

56. Honda T, Nakajima S, Egawa G, Ogasawara K, Malissen B, Miyachi Y, et al. Compensatory role of Langerhans cells and langerin-positive dermal dendritic cells in the sensitization phase of murine contact hypersensitivity. J Allergy Clin Immunol 2010;125:1154-1156 e2

57. Murakami R, Denda-Nagai K, Hashimoto S, Nagai S, Hattori M, Irimura T. A Unique Dermal Dendritic Cell Subset That Skews the Immune Response toward Th2. PLoS One 2013;8:e73270.

58. Oyoshi MK, Larson RP, Ziegler SF, Geha RS. Mechanical injury polarizes skin dendritic cells to elicit a $T(H) 2$ response by inducing cutaneous thymic stromal lymphopoietin expression. J Allergy Clin Immunol 2010;126:97684,984 e1-5

59. Ito T, Wang YH, Duramad O, Hori T, Delespesse GJ, Watanabe $\mathrm{N}$, et al. TSLP-activated dendritic cells induce an inflammatory Thelper type 2 cell response through OX40 ligand. J Exp Med 2005;202:1213-23

60. Di Cesare A, Di Meglio P, Nestle FO. The IL-23/Th17 axis in the immunopathogenesis of psoriasis. J Invest Dermatol 2009;129:1339-50

61. Krueger GG, Langley RG, Leonardi C, Yeilding N, Guzzo C, Wang $Y$, et al. A human interleukin-12/23 monoclonal antibody for the treatment of psoriasis. N Engl J Med 2007;356:580-92

62. Leonardi CL, Kimball AB, Papp KA, Yeilding N, Guzzo C, Wang $Y$, et al. Efficacy and safety of ustekinumab, a human interleukin-12/23 monoclonal antibody, in patients with psoriasis: 76-week results from a randomised, double-blind, placebo-controlled trial (PHOENIX 1). Lancet 2008;371:1665-74

63. Zaba LC, Cardinale I, Gilleaudeau P, Sullivan-Whalen M, Suarez-Farinas M, Fuentes-Duculan J, et al. Amelioration of epidermal hyperplasia by TNF inhibition is associated with reduced Th17 responses. J Exp Med 2007;204:3183-94

64. Wohn C, Ober-Blobaum JL, Haak S, Pantelyushin S, Cheong C, Zahner SP, et al. Langerin(neg) conventional dendritic cells produce IL-23 to drive psoriatic plaque formation in mice. Proc Natl Acad Sci U S A 2013;110:10723-8

65. Yoshiki R, Kabashima K, Honda T, Nakamizo S, Sawada Y, Sugita K, et al. IL-23 from Langerhans cells is required for the development of imiquimod-induced psoriasis-like dermatitis by induction of IL-17A-producing gammadelta T cells. J Invest Dermatol 2014;134:1912-21

66. Glitzner E, Korosec A, Brunner PM, Drobits B, Amberg N, Schonthaler HB, et al. Specific roles for dendritic cell sub- 
sets during initiation and progression of psoriasis. EMBO Mol Med 2014; 6: 1312-27

67. Tortola L, Rosenwald E, Abel B, Blumberg H, Schafer M, Coyle AJ, et al. Psoriasiform dermatitis is driven by IL-36-mediated DC-keratinocyte crosstalk. J Clin Invest 2012;122:3965-76

68. Taylor PR, Martinez-Pomares L, Stacey M, Lin HH, Brown $\mathrm{GD}$, Gordon $S$. Macrophage receptors and immune recognition. Annu Rev Immunol 2005;23:901-44

69. Akira S, Takeda K, Kaisho T. Toll-like receptors: critical proteins linking innate and acquired immunity. Nat Immunol 2001;2:675-80

70. Inohara N, Nunez G. NODs: intracellular proteins involved in inflammation and apoptosis. Nat Rev Immunol 2003;3:371-82

71. Gordon S. Alternative activation of macrophages. Nat Rev Immunol 2003; 3: 23-35

72. Sica A, Mantovani A. Macrophage plasticity and polarization: in vivo veritas. J Clin Invest 2012;122:787-95

73. Martinez FO, Helming L, Gordon S. Alternative Activation of Macrophages: An Immunologic Functional Perspective. Ann Rev of Immunol 2009;27:451-483

74. Kreider T, Anthony RM, Urban JF, Gause WC. Alternatively activated macrophages in helminth infections. Curr Opin Immunol 2007;19:448-453

75. Murray PJ, Wynn TA. Protective and pathogenic functions of macrophage subsets. Nat Rev Immunol2011;11:723-37

76. Passlick B, Flieger D, Ziegler-Heitbrock HW. Identification and characterization of a novel monocyte subpopulation in human peripheral blood. Blood 1989;74:2527-34

77. Egawa M, Mukai K, Yoshikawa S, Iki M, Mukaida N, Kawano $Y$, et al. Inflammatory monocytes recruited to allergic skin acquire an anti-inflammatory M2 phenotype via basophil-derived interleukin-4. Immunity 2013;38:570-80

78. Gordon EJ, Rao S, Pollard JW, Nutt SL, Lang RA, Harvey NL. Macrophages define dermal lymphatic vessel calibre during development by regulating lymphatic endothelial cell proliferation. Development 2010;137:3899-910

79. Abtin A, Jain R, Mitchell AJ, Roediger B, Brzoska AJ, Tikoo $S$, et al. Perivascular macrophages mediate neutrophil recruitment during bacterial skin infection. Nat Immunol 2014;15:45-53

80. Egawa G, Kabashima K. Skin as a Peripheral Lymphoid Organ: Revisiting the Concept of Skin-Associated Lymphoid Tissues. J Invest Dermatol 2011;131:2178-2185

81. Clark RA. Skin-resident T cells: the ups and downs of on site immunity. J Invest Dermatol 2010;130:362-70

82. Kupper TS, Fuhlbrigge RC. Immune surveillance in the skin: mechanisms and clinical consequences. Nat Rev Immunol 2004;4:211-22

83. Honda T, Egawa G, Grabbe S, Kabashima K. Update of immune events in the murine contact hypersensitivity model: toward the understanding of allergic contact dermatitis. J Invest Dermatol 2013; 133: 303-15

84. Kim BS, Wojno ED, Artis D. Innate lymphoid cells and allergic inflammation. Curr Opin Immunol 2013;25:738-44

85. Kurebayashi Y, Nagai S, Ikejiri A, Koyasu S. Recent advances in understanding the molecular mechanisms of the development and function of Th17 cells. Genes Cells 2013;18:247-65

86. Xing L, Dai Z, Jabbari A, Cerise JE, Higgins CA, Gong W, et al. Alopecia areata is driven by cytotoxic $T$ lymphocytes and is reversed by JAK inhibition. Nat Med 2014;20: 1043-9
87. Shiohara T. Fixed drug eruption: pathogenesis and diagnostic tests. Curr Opin Allergy Clin Immunol 2009;9:31621

88. Nomura T, Kabashima K, Miyachi Y. The panoply of alpha beta T cells in the skin. J Dermatol Sci 2014;76:3-9

89. Mueller SN, Gebhardt T, Carbone FR, Heath WR. Memory T Cell Subsets, Migration Patterns, and Tissue Residence. Ann Rev Immunol Vol 31 2013; 31: 137-161

90. Schenkel JM, Masopust D. Tissue-Resident Memory T Cells. Immunity 2014;41:886-97

91. Brandtzaeg P, Pabst R. Let's go mucosal: communication on slippery ground. Trends Immunol 2004;25:570-7

92. Toews GB, Bergstresser PR, Streilein JW. Langerhans cells: sentinels of skin associated lymphoid tissue. J Invest Dermatol 1980;75:78-82

93. Rubenfeld MR, Silverstone AE, Knowles DM, Halper JP, De Sostoa A, Fenoglio CM, et al. Induction of lymphocyte differentiation by epidermal cultures. J Invest Dermatol 1981;77:221-4

94. Moyron-Quiroz JE, Rangel-Moreno J, Kusser K, Hartson L, Sprague $F$, Goodrich S, et al. Role of inducible bronchus associated lymphoid tissue (BALT) in respiratory immunity. Nat Med 2004;10:927-34

95. lijima N, Iwasaki A. T cell memory. A local macrophage chemokine network sustains protective tissue-resident memory CD4 T cells. Science 2014;346:93-8

96. Girard-Madoux MJ, Kel JM, Reizis B, Clausen BE. IL-10 controls dendritic cell-induced $\mathrm{T}$-cell reactivation in the skin to limit contact hypersensitivity. J Allergy ClinImmunol 2012;129:143-50 e1-10

97. Lew W, Bowcock AM, Krueger JG. Psoriasis vulgaris: cutaneous lymphoid tissue supports T-cell activation and "Type 1“ inflammatory gene expression. Trends Immunol 2004:25:295-305

98. Johnson-Huang LM, Suarez-Farinas M, Pierson KC, Fuentes-Duculan J, Cueto I, Lentini T, et al. A single intradermal injection of IFN-gamma induces an inflammatory state in both non-lesional psoriatic and healthy skin. J Invest Dermatol 2012;132:1177-87

99. Kim BS, Wang K, Siracusa MC, Saenz SA, Brestoff JR, Monticelli LA, et al. Basophils promote innate lymphoid cell responses in inflamed skin. J Immunol 2014;193: $3717-25$

100. Magro CM, Crowson AN, Kovatich AJ, Burns F. Lupus profundus, indeterminate lymphocytic lobular panniculitis and subcutaneous T-cell lymphoma: a spectrum of subcuticular T-cell lymphoid dyscrasia. J Cutan Pathol 2001;28:235-247

101. Massone C, Kodama K, Salmhofer W, Abe R, Shimizu H, Parodi A, et al. Lupus erythematosus panniculitis (lupus profundus): Clinical, histopathological, and molecular analysis of nine cases. J Cutan Pathol 2005;32:396-404

102. Bagabir R, Byers RJ, Chaudhry IH, Muller W, Paus R, Bayat A. Site-specific immunophenotyping of keloid disease demonstrates immune upregulation and the presence of lymphoid aggregates. Br J Dermatol 2012;167:1053-66

103. Ploysangam T, Breneman DL, Mutasim DF. Cutaneous pseudolymphomas. J Am Acad Dermatol 1998;38:877-895

104. Lackey JN, Xia Y, Cho S, Sperling LC. Cutaneous lymphoid hyperplasia: a case report and brief review of the literature. Cutis 2007;79:445-8

105. Ono S, Kabashima K.Proposal of skin associated lymphoid tissue. Exp Dermatol 2015; 24:630-1 